\title{
ENTRE O ESTADO E O MERCADO: UMA ANÁlISE DE POLÍTICAS PÚBLICAS DE EDUCAÇÃO NO BRASIL
}

\begin{tabular}{|c|}
\hline $\begin{array}{c}\text { BETWEEN THE STATE AND THE MARKET: } \\
\text { AN ANALYSIS OF PUBLIC EDUCATION POLITICS IN BRAZIL }\end{array}$ \\
\hline $\begin{array}{c}\text { ENTRE EL ESTADO Y EL MERCADO: } \\
\text { UN ANÁLISIS DE POLÍTICAS PÚBLICAS DE EDUCACIÓN EN BRASIL }\end{array}$ \\
\hline $\begin{array}{l}\text { Alana das Neves Pedruzzi }{ }^{1} \\
\text { Tamires Lopes Podewils } \\
\text { Fernando Nunes Oliveira }\end{array}$ \\
\hline $\begin{array}{l}\text { RESUMO: O presente artigo procura explicitar o quadro de múltiplas relações entre as Políticas Públicas de } \\
\text { Educação brasileiras e os interesses do grande Capital, tendo o mercado como seu artífice. Para tanto, são } \\
\text { analisados documentos de organismos internacionais como Banco Mundial, a legislação brasileira pertinente à } \\
\text { Educação, dialogando também com referenciais da Educação brasileira que procuram discutir tais imbricações } \\
\text { entre Estado e Mercado. Assim, são organizadas duas subdivisões com a intencionalidade de discorrer, } \\
\text { primeiramente, sobre as influências neoliberais na Educação durante os governos de FHC, Lula e Dilma; e, em } \\
\text { segundo momento, sobre a explicitação dos interesses do mercado no governo Temer. Por fim, argumenta-se } \\
\text { contra a relação íntima entre Estado e Mercado, pensando os desdobramentos de tal ligação para as práticas }\end{array}$ \\
\hline
\end{tabular}

PALAVRAS-ChAVE: Educação. Políticas públicas. Mercado.

ABSTRACT: The present paper aims at presenting the picture of multiple relations between Brazilian Public Policies of Education and the interests of big business, with market as its perpetrator. In order to do so, documents from international organizations such as the World Bank and the Brazilian legislation related to Education, are analyzed, as well as the references of Brazilian Education that discuss imbrications between State and Market. Thus, two sections are organized with the intent of discussing, the neoliberal influences on the Education during the administrations of FHC, Lula and Dilma; and, explaining market interests in Temer administration. Finally, we argued against the intimate relation between State and Market, considering the consequences of such link for teaching practices.

KEYWORDS: Education. Public policies. Market.

RESUMÉN: El presente artículo busca explicitar el cuadro de múltiples relaciones entre las Políticas Públicas de Educación brasileñas y los intereses del gran Capital, teniendo el mercado como su artífice. Para ello, se analizan documentos de organismos internacionales como Banco Mundial, la legislación brasileña pertinente a la Educación, dialogando también con referenciales de la Educación brasileña que buscan discutir tales imbricciones entre Estado y Mercado. Así, se organizan dos subdivisiones con la intencionalidad discurrir, primero, sobre las influencias neoliberales en la Educación durante los gobiernos de FHC, Lula y Dilma; y, en segundo momento, sobre la explicitación de los intereses del mercado en el gobierno Temer. Por último, se argumenta contra la relación íntima entre Estado y Mercado, pensando los desdoblamientos de tal vínculo para las prácticas docentes.

PALABRAS ClAvE: Educación. Políticas públicas. Mercado.

Submetido em: 07/02/2018 - Aceito em: 20/02/2018 - Publicado em: 03/06/2018

\begin{tabular}{l|l|l|l|l|l|l} 
(C) Rev. Educ. Perspec. & Viçosa, $M G$ & v.9 & n.1 & p.174-191 & jan./abr. 2018 & eISSN 2178-8359 \\
\hline
\end{tabular}




\section{INTRODUÇÃO}

$\mathrm{Na}$ medida em que nos propomos analisar o processo educativo e o cotidiano da prática docente no Brasil, nos deparamos com inúmeras condições que interpelam o desenvolvimento de práticas educativas de qualidade socialmente referenciada. Não raro vemos pesquisadores da área da Educação estabelecendo diálogos que questionam as condições materiais que envolvem a totalidade da Educação. Nestes diálogos surgem questões tanto de abrangência geral, como o sucateamento das instalações de ensino, baixa remuneração dos docentes e falta de investimento em recursos didáticos, quanto particularidades que envolvem não só o profissional docente, mas também o conjunto do corpo escolar, equipe diretiva e estudantes, e as condições materiais com que estes chegam ao ambiente educativo.

É consenso no debate educacional que a falta de recursos financeiros - públicos e particulares - afeta de forma contundente a qualidade das práticas desenvolvidas em sala de aula, pois, a fim de que os docentes possam desenvolver boas aulas e os estudantes bons estudos é necessário que se verifique uma série de questões prioritárias, como o acesso qualificado ao ambiente escolar, materiais escolares adequados, vestimentas que possibilitem conforto e mesmo uma boa alimentação para desenvolver uma rotina de estudos. Todas estas são questões que, por mais cotidianas que sejam geram impactos significativos na qualidade do ensino e da aprendizagem desenvolvida nas salas de aula. Dada a importância de tais questões é necessário que se discuta qual o peso destas no desenvolvimento do processo educativo e como estas vem sendo enfrentadas a partir das políticas públicas brasileiras.

A importância de debater os condicionantes materiais que permeiam o processo educativo está em recolocar no debate social a importância de questionarmos a base material que propicia o processo educativo. É por este motivo que se faz fundamental olhar para o financiamento da educação brasileira procurando encontrar os motivos pelos quais esta tem tomado determinados caminhos.

Para evidenciar tal linha de raciocínio destacamos duas seções neste artigo a fim de que possamos melhor compreender o movimento das políticas públicas de Educação no Brasil e as influências neoliberais ${ }^{i}$ dispostas nestas políticas. Na primeira seção apontamos alguns movimentos das políticas públicas durante os governos de Fernando Henrique Cardoso, Luiz Inácio Lula da Silva e Dilma Rousseff, a fim de estabelecer as relações e divergências nas posições destes governos em relação aos interesses do grande Capital. Na segunda seção, por sua vez, nos dedicamos a refletir sobre as relações dos projetos de Educação desenvolvidos no governo de Michel Temer, explicitando a relação direta de atendimento dessas políticas para com os interesses dos organismos internacionais, do capital estrangeiro e do privatismo.

\begin{tabular}{|c|c|c|c|c|c|c|} 
(C) Rev. Educ. Perspec. & Viçosa, $M G$ & v.9 & n.1 & p.174-191 & jan./abr. 2018 & eISSN 2178-8359 \\
\hline
\end{tabular}


Por fim, no tópico destinado às considerações finais, procuramos sustentar a ideia de que existe um vínculo orgânico entre algumas políticas públicas brasileiras e os interesses internacionais do Capital, dialogando ainda sobre o impacto desses interesses no que fazemos enquanto docentes. Procuramos, desta forma, destacar a importância da discussão sobre esses pressupostos que se impõem às práticas educativas dos docentes.

Em relação aos processos metodológicos o artigo procura evidenciar resultados de uma pesquisa de cunho bibliográfico, em que foram considerados alguns referenciais que dialogam sobre a área da Educação, mais especialmente no que se refere às políticas públicas de financiamento da Educação, como Boito Junior (1998), Chauí (1999), Leher (1999) e Chaves (2010). Para compor o debate aqui desenvolvido foram elencados alguns documentos de organismos internacionais (BANCO MUNDIAL, 1995; 1996) e legislações que foram mais recorrentes nas leituras dos referenciais da área da Educação (BRASIL, 2005; 2010), conjugando também outros documentos de caráter mais atual que consideramos importantes ao debate (BANCO MUNDIAL, 2011; 2017; BRASIL, 2016; 2017; 2018).

\section{A INFLUÊNCIA NEOLIBERAL NA EDUCAÇÃO BRASILEIRA}

Já na década de 1990 diversos pesquisadores brasileiros se dedicaram a estabelecer um vínculo de caráter orgânico entre o financiamento da Educação e as políticas oferecidas no Estado brasileiro, entendendo que as estratégias de alocação de recursos na educação brasileira cumprem uma agenda maior do que os interesses próprios da Educação, sendo regida por interesses do capital estrangeiro, de grandes conglomerados industriais e midiáticos e mesmo de organismos internacionais que se apresentam como entidades neutras. Leher (1999), ao tecer análise sobre as políticas neoliberais para a educação, especialmente aquelas fomentadas a partir das diretrizes do Banco Mundial e do Fundo Monetário Internacional - FMI, apresenta um quadro de envolvimento direto destes organismos para com as políticas públicas de Educação desenvolvidas no Brasil a partir da década de 1980.

No documento intitulado "Prioridades y estrategias para La educación" o Banco Mundial (1996) desenvolve movimento inédito em seu histórico de financiamento, passando a elencar áreas como saúde e educação como estratégicas para o controle dos estados. Este movimento, conforme ressalta Leher (1999), se diferencia do que havia sido concretizado até então enquanto projeto de financiamento deste organismo. Se antes a Educação e a Saúde eram consideradas áreas de menor interesse, a partir de 1980, e mais intensamente na década de 1990 passam a ser consideradas áreas importantes ao controle social dos estados que aderiam com pouca - ou quase nenhuma - ressalva ao neoliberalismo. 
Tal cenário não se constitui em momento exclusivo do governo de ordem explicitamente neoliberal de Fernando Henrique Cardoso (FHC) (1995 - 2002), sendo parcialmente adotado também nos governos de Luiz Inácio Lula da Silva (2003 - 2011), de Dilma Rousseff (2011 2016), e atualmente, revigorado sob o comando de Michel Temer (2016 -). Se na década de 1990 as Instituições Federais de Ensino Superior - IFES e a educação básica sofreram com as políticas públicas de caráter neoliberal, o início do século XXI marca a retomada dos investimentos públicos na Educação (DAVIES, 2004; LIMA, 2011).

Pontos fora da curva do panorama de investimentos na Educação Pública da década de 1990 foram a implantação da Lei de Diretrizes e Bases da Educação Nacional - LDBEN, Lei $n^{\circ}$ 9.394/96 (BRASIL, 1996), e a implementação do Fundo de Manutenção e Desenvolvimento do Ensino Fundamental e de Valorização do Magistério - FUNDEF, instituído em 1996, regulamentado em 1997 e implantado nacionalmente a partir de janeiro de 1998. Mencionamos a peculiaridade de tais ações, pois estas se constituem como importantes iniciativas de valorização da educação pública no Brasil. A LDBEN elaborada em 1996, por exemplo, viria a ser o primeiro passo de maior magnitude no sentido de redirecionar a educação pública, regulamentada majoritariamente até então por legislação oriunda do período ditatorial brasileiro. Nesta o Estado brasileiro passa a garantir os investimentos públicos em Educação a partir da obrigatoriedade de percentual mínimo de investimento, conforme consta no artigo 69 da Lei no 9.394/96 (BRASIL, 1996). O FUNDEF, por sua vez, seria a constituição de fundo específico para o financiamento da Educação, com alocação de recursos oriundos de impostos e transferências de estados. A importância deste fundo está não só em garantir o financiamento diretamente à Educação, mas também por ser o parâmetro-base para elaboração do Fundo de Manutenção e Desenvolvimento da Educação Básica e de Valorização dos Profissionais da Educação - FUNDEB ${ }^{\text {ii }}$ (BRASIL, 2006).

Tais elementos, positivamente mencionados nos debates educativos, não constituíram o quadro geral que marcaria o governo FHC e os primeiros anos do século XXI. Este cenário seria parcialmente modificado a partir da ascensão do governo Lula, quando houve uma retomada nos investimentos públicos na Educação. A partir de uma análise preliminar é possível depreender uma franca expansão da educação pública nos governos do Partido dos Trabalhadores (PT). Para exemplificar tal situação, conforme dados do Ministério da Educação (MEC) (BRASIL, 2012) notamos um aumento no número de Universidades Federais, Institutos Federais, ampliação de vagas no Ensino Superior, contratação progressiva de docentes e profissionais técnicos em educação, bem como um grande aumento no número de cidades atendidas pelo Ensino Superior Público.

No entanto, para além da visível expansão no que se refere ao investimento no ensino público, no período de 2003 a 2016 verificou-se também uma inflexão no sentido de incorporar nas estratégias para a Educação Pública no Brasil um maior diálogo para com os

\begin{tabular}{l|c|c|c|c|c|c|} 
(C) Rev. Educ. Perspec. & Viçosa, $M G$ & v.9 & n.1 & p.174-191 & jan./abr. 2018 & eISSN 2178-8359 \\
\hline
\end{tabular}


movimentos sociais, organizações civis, categorias profissionais da educação, sindicatos e sociedade civil. Exemplo disso é a implementação da Lei no 10.639 , que data do início de 2003 e dispõe sobre o ensino da cultura Afro-Brasileira (BRASIL, 2003), e do aprimoramento desta, conforme Lei no 11.645 de março de 2008 (BRASIL, 2008), que estabelece a obrigatoriedade do ensino da Cultura Afro-Brasileira e Indígena nos currículos brasileiros. Também durante a vigência dos governos do Partido dos Trabalhadores foi decretada a obrigatoriedade do ensino de Filosofia e Sociologia nos currículos do Ensino Médio, via Lei n 11.684 de junho de 2008 (BRASIL, 2008a).

Vemos, portanto, que em uma análise superficial, houve uma evidente expansão e qualificação da Educação Pública durante os governos do Partido dos Trabalhadores, tanto no que se refere aos investimentos na Educação Básica e Ensino Superior, quanto à incorporação de saberes antes alijados, ou menorizados, nos currículos brasileiros. Tal situação, entretanto, não esconde o caráter de desenvolvimento das estratégias neoliberais que também vigoraram nestes governos. Ainda que neste período tenhamos visto um projeto expansionista em relação à Educação, foi possível percebermos também que os interesses do mercado, dos organismos internacionais e das grandes corporações não foram lesados, sendo, pelo contrário, foco também da grande expansão na Educação brasileira.

Em consonância com as diretrizes estabelecidas pelo Banco Mundial em diversas publicações, vemos que, a título de exemplo, no Ensino Superior já no ano de 2004 iniciaram os projetos com objetivo de expandir a oferta de vagas e as estruturas físicas das Instituições de Ensino Superior - IES. Em janeiro de 2005, por meio da Lei $\mathrm{n}^{\mathrm{o}} 11.096$ foi instituído o Programa Universidade para Todos - PROUNI, com o objetivo principal de conceder bolsas de estudo integrais e parciais para estudantes de cursos de graduação e sequenciais de formação específica, em instituições privadas de ensino superior, com ou sem fins lucrativos (BRASIL, 2005). Já em abril de 2007 foi promulgado o Decreto $n^{\circ} 6.096$ que instituiu o Programa de Apoio a Planos de Reestruturação e Expansão das Universidades Federais REUNI, com o objetivo de criar condições para a ampliação do acesso e permanência na educação superior, no nível de graduação, pelo melhor aproveitamento da estrutura física e de recursos humanos existentes nas universidades federais (BRASIL, 2007). Em janeiro de 2010, por meio da promulgação da Lei $\mathrm{n}^{\circ} 12.202$ foi estabelecida a reforma dos programas de crédito estudantil no Brasil, sendo criado o Fundo de Financiamento ao Estudante do Ensino Superior - FIES, com a intenção de oferecer financiamento estudantil para alunos regularmente matriculados em cursos superiores não gratuitos (BRASIL, 2010).

Dentre as inúmeras ações que nos possibilitariam analisar o cenário de expansão do ensino público brasileiro, a escolha dos três programas mencionados no parágrafo anterior se deu em virtude destes exemplificarem as relações de proximidade das estratégias educativas dos governos brasileiros para com as orientações emitidas por organismos internacionais como

\begin{tabular}{|c|c|c|c|c|c|c|} 
(C) Rev. Educ. Perspec. & Viçosa, $M G$ & v.9 & n.1 & p.174-191 & jan./abr. 2018 & eISSN 2178-8359 \\
\hline
\end{tabular}


Banco Mundial e FMI (LIMA, 2011). Esta situação fica evidente não só pelo caráter de investimento direto de recursos públicos em instituições de ensino superior privadas por via de programas como PROUNI e FIES, mas também pelas circunstâncias que envolvem o processo de expansão desencadeado pelo programa REUNI, pois ao mesmo tempo em que eram ofertadas novas vagas no Ensino Superior Público, também eram exigidas contrapartidas em relação às elaborações curriculares e organizacionais do quadro de profissionais docentes. Assim, fica claro o movimento de, por um lado injetar recursos públicos diretamente na iniciativa privada, e por outro, atender às recomendações dos organismos internacionais via readequação dos cursos de graduação e da razão professor X aluno.

Tal situação fica explícita quando analisamos os dados referentes ao investimento público nos programas citados. Segundo Mendes (2015, p. 4), em análise que considera apenas o período entre $2004-2014$ :

\begin{abstract}
O maior destaque fica para a expansão do financiamento para estudantes de ensino superior matriculados em escolas privadas. Esse programa, conhecido como "Fundo de Financiamento Estudantil (FIES)", já é o maior item de desembolso federal em educação, a exceção dos gastos em pessoal. Consumiu R \$ 13,8 bilhões em 2014, o que representa um crescimento real de $1.100 \%$ em relação às cifras de 2004. Sozinho já representa $15 \%$ de toda a despesa federal em educação.
\end{abstract}

A isso se somam os repasses à iniciativa privada por meio do PROUNI, que, segundo Mendes (2015), só em 2014 aportaram 601 milhões de reais no ensino privado. Estes subsídios financeiros ofertados ao setor privado ficam ainda mais alarmantes a partir dos seguintes dados:

Tomemos como exemplo o FIES. Em apenas quatro anos, entre 2010 e 2014, os gastos com o programa cresceram de R\$ 1,2 bilhões para $\mathrm{R} \$ 13,8$ bilhões. Multiplicaram-se os alunos e as escolas privadas financiadas pelo programa. Várias dessas escolas viraram potências empresariais, com ações em bolsa de valores, financiadas principalmente pelos recursos do programa (MENDES, 2015, p. 8).

Em direta comparação é possível atentarmos aos dados de investimento no setor público no mesmo período, em que menciona Mendes (2015) que no período entre 2003 - 2014, com a criação de 18 novas Universidades Federais e aumento expressivo no número de vagas e instalações físicas das Universidades, o investimento nas Universidades Públicas ainda não havia se aproximado do aporte à iniciativa privada. A título de exemplo, em 2014, os investimentos públicos nas Universidades Federais foram de 8,8 bilhões (MENDES, 2015).

A análise de Mendes (2015) aponta ainda para outro grande problema do investimento direto de recursos públicos na iniciativa privada, sendo a financeirização e capitalização internacional das iniciativas privadas no setor educacional. Conforme Chaves (2010, p. 491): 


\begin{abstract}
Além das fusões, que têm formado gigantes da educação, as "empresas de ensino" agora abrem o capital na bolsa de valores, com promessa de expansão ainda mais intensa e incontrolável. São quatro as empresas educacionais que mais se destacam nesse mercado de capitais: a Anhanguera Educacional S.A., com sede em São Paulo; a Estácio Participações, controladora da Universidade Estácio de Sá, do Rio de Janeiro; a Kroton Educacional, da Rede Pitágoras, com sede em Minas Gerais; e a empresa SEB S.A., também conhecida como "Sistema COC de Educação e Comunicação", com sede em São Paulo. É importante ressaltar que grande parte do capital dessas empresas é oriunda de grupos estrangeiros, em especial, de bancos de investimentos norte-americanos, que encontraram, nesse setor, um mercado muito favorável ao aumento de seus lucros.
\end{abstract}

Cabe ressaltarmos que os dados levantados pela autora demonstram o potencial financeiro das redes de ensino privadas. No entanto, se tais informações soam como alarmantes diante do cenário de completa dominação financeira do sistema privado de ensino no Brasil, a situação torna-se mais grave a partir da atualização de tais informações, vide fusão entre as gigantes do setor privado Kroton Educacional e Anhanguera Educacional S.A., autorizadas pelo Conselho Administrativo de Defesa Econômica - CADE em 2014. O cenário só não se tornou pior diante do veto do CADE à fusão da Kroton Educacional com a também gigantesca rede de ensino privado Estácio Participações. Tal veto se deu pelo entendimento do comitê antitruste de que a fusão daria à Kroton Educacional um domínio desproporcional no setor privado da educação, impossibilitando a concorrência justa no setor.

A relação entre as diretrizes do financiamento educativo no Brasil e as estratégias dos organismos internacionais fica ainda mais clara ao considerarmos o cenário de mega investimento no setor privado e as indicações do Banco Mundial em suas publicações. Segundo documento intitulado "La enseñanza superior: Las lecciones derivadas de la Experiencia", o Banco Mundial deixa evidente a importância do setor privado ao estabelecer que:

La introducción de una mayor diferenciación en la enseñanza superior, es decir, la creación de instituciones no universitarias y el aumento de instituciones privadas, puede contribuir a satisfacer la demanda cada vez mayor de educación postsecundaria y hacer que los sistemas de enseñanza se adecúen mejor a las necesidades del mercado de trabajo (BANCO MUNDIAL, 1995, p. 31).

A insistência por parte do Banco Mundial na necessidade de reformas educacionais nos países tidos como "parceiros" é reforçada em diversas publicações do grupo, na qual fica nítida a ideia de que mesmo com a melhora global nos índices de matrículas no Ensino Básico e no Ensino Superior, há, mormente, uma Crise de Aprendizagem, novo conceito principal das estratégias de inserção das diretrizes do Banco Mundial nas economias nacionais. Conforme documento intitulado "Aprendizagem para todos: Investir nos conhecimentos e competências das pessoas para promover o desenvolvimento":

No âmbito do Grupo Banco Mundial, o Banco Mundial e a IFC trabalharão em conjunto para aumentar o conhecimento sobre o papel do sector privado na 
educação e ajudar os países a criar ambientes de política e estruturas normativas que alinhem os esforços do sector privado por meio de parcerias estratégicas nos níveis tanto internacional como dos países, a fim de melhorar os sistemas educacionais (BANCO MUNDIAL, 2011, p. 13, grifo nosso).

De acordo com as publicações do Banco Mundial, é possível perceber uma forte preocupação em ressaltar a importância do setor privado no desenvolvimento educacional dos países parceiros, este, por sua vez, viria a contribuir para o desenvolvimento tanto do mercado interno, por via de qualificação de mão de obra, quanto à economia internacional, por meio da adequação das economias nacionais ao ideário neoliberal. Percebendo este movimento, Chauí estabelece que:

A reforma do Estado tem um pressuposto ideológico básico: o mercado é, portanto,
de racionalidade sócio-política e agente principal do bem estar da república. Esse
pressuposto leva a colocar direitos sociais (como a saúde, a educação e a cultura) no
setor de serviços definidos pelo mercado. Dessa maneira, a reforma encolhe o
espaço público democrático de direitos e amplia o espaço privado não só ali onde
seria previsível - nas atividades ligadas à produção econômica -, mas também onde
não é admissível - no campo dos direitos sociais conquistados (CHAUÍ, 1999, p. 3).

Se tal cenário de relação orgânica entre a Educação brasileira e os interesses do mercado e organismos internacionais foi explicitamente incentivado no governo FHC, nos governos do Partido dos Trabalhadores - Governos Lula e Dilma - tal relação não foi menos benéfica ao capital estrangeiro, ao mercado e a tais organismos. Conforme dados apresentados anteriormente, os números relativos aos aportes financeiros na iniciativa privada deixam claras as benesses dadas pelos governos brasileiros a esta. No entanto, é necessário, a título de contextualização do cenário político e educativo, considerar que tais governos, ainda que em segunda instância, apresentam diferenças em relação ao entendimento do investimento no ensino público. São inegáveis os índices de escolarização básica e acesso ao ensino superior decorrentes dos governos petistas e mesmo a retomada por estes governos de questões de direcionamento político, minimamente divergentes do ideário neoliberal.

Ainda que consideremos a prioridade de investimentos privados na educação brasileira nas últimas décadas, é possível percebermos, de forma sintomática, que as Instituições de Ensino Superior Públicas e a Educação Básica se desenvolveram fortemente. A partir dos desdobramentos do fim dos governos petistas e imensamente motivado pela forte crise financeira mundial, o cenário da Educação Pública brasileira voltaria a viver tempos de cortes sucessivos já iniciados nos governos de Dilma Rousseff e amplamente difundidos e defendidos pelo governo de Michel Temer. 


\section{O GOVERNO TEMER E A EXPLICITAÇÃO DOS INTERESSES DO MERCADO NA EDUCAÇÃO BRASILEIRA}

Dada a análise que vimos fazendo até este momento, poderíamos seguir nossa linha de raciocínio apontando para as múltiplas relações entre o governo de Michel Temer e as exigências do mercado financeiro e dos organismos internacionais. Já afirmamos anteriormente que nenhum dos governos, nas últimas décadas, que incluem as gestões de FHC, Lula e Dilma podem ser considerados excrescências na valorização do Ensino Público em detrimento do setor educacional privado. Sendo assim, poderíamos, sem prejuízo à nossa argumentação, continuar sustentando o movimento do governo de Michel Temer em uma linha argumentativa similar ao que fizemos até aqui. No entanto, consideradas as ações explícitas de enfraquecimento da Educação Pública praticadas por este governo, julgamos necessário estabelecer um tópico em separado para tratarmos do caráter das políticas públicas realizadas de meados de 2016 até o momento.

Uma das primeiras ações do governo Temer, que indicou o caráter com que seria tratada a Educação durante seu governo, foi a nulidade das designações feitas pela presidente anteriormente em exercício para a composição do Conselho Nacional de Educação - CNE. Em um dos seus últimos atos administrativos a presidente Dilma Rousseff havia designado para a composição do CNE os conselheiros indicados por grupos da sociedade civil, categorias sindicais, representantes de entidades com vinculação à temática da Educação e docentes federais, respeitando a lista tríplice encaminhada pelas mesmas entidades. Ainda que houvesse a prerrogativa de recomendação de 12 das 24 vagas no Conselho, as indicações - com validade de quatro anos - respeitaram as indicações dos movimentos sociais. Em junho de 2016, o presidente Michel Temer revoga esta e impõe nova configuração ao Conselho Nacional de Educação, conforme (BRASIL, 2016).

A importância deste ato, para além do óbvio respeito à composição socialmente indicada pelos movimentos sociais e entidades civis, está no papel que este conselho representa de acordo com o estipulado pela LDBEN de 1996, em que fica explícita a responsabilidade deste conselho na elaboração da Base Nacional Comum Curricular - BNCC. A BNCC é responsável pela indicação dos conteúdos a serem cumpridos no Ensino Básico, motivo pelo qual se torna alvo de diversos interesses públicos e privados.

As alterações nas políticas educacionais realizadas no governo Temer se mostram de caráter absolutamente favorável às disposições dos organismos internacionais, dentre os quais, sem sombra de dúvidas, o Banco Mundial constitui um destaque. Ao analisarmos as rápidas mudanças implementadas neste governo é possível encontrar coincidência com as concepções expostas pelo Banco Mundial tanto nos documentos que citamos anteriormente, quanto em outras diretrizes elaboradas especificamente para o Brasil.

\begin{tabular}{l|c|c|c|c|c|c} 
(c) Rev. Educ. Perspec. & Viçosa, $M G$ & v.9 & n.1 & p.174-191 & jan./abr. 2018 & eISSN 2178-8359 \\
\hline
\end{tabular}


Se em diversas publicações do Banco Mundial (1995; 2011) vemos a explicitação das necessidades dos países parceiros realizarem reformas e ajustes nos sistemas educacionais, em relatório elaborado a pedido do governo brasileiro, e divulgado em novembro de 2017, os direcionamentos especificam com exatidão os planos a serem desenvolvidos pelo país a fim de que a economia nacional seja estabilizada, se cumpra a meta fiscal e o país atinja um desenvolvimento superavitário (BANCO MUNDIAL, 2017). No documento intitulado "Um Ajuste Justo: Análise da eficiência e equidade do gasto público no Brasil", o Grupo Banco Mundial aponta para as ações a serem desenvolvidas pelo estado brasileiro para que se atinja o equilíbrio fiscal. Diversas são as áreas em que o estudo apresenta possíveis ações, dentre elas o funcionalismo público, assistência social, previdência social, saúde e educação.

No tocante à área da Educação, três eixos prioritários de reforma são analisados: o primeiro que diz respeito às despesas públicas com o Ensino Fundamental e Ensino Médio; o segundo, que trata da vinculação constitucional de $25 \%$ das receitas municipais à área da Educação e o terceiro diz respeito à ineficiência das despesas públicas com o Ensino Superior (BANCO MUNDIAL, 2017). Em relação ao primeiro dos três eixos prioritários apontados pelo documento vemos que:

A ineficiência dos ensinos fundamental e médio está principalmente relacionada ao número excessivo de professores. Aproximadamente $39 \%$ da ineficiência dos gastos brasileiros com educação estão associados às baixas razões aluno-professor (RAP). Se todas as escolas atingissem a fronteira de desempenho, o Brasil poderia aumentar o número de estudantes por professor em $33 \%$ no ensino fundamental e em $41 \%$ no ensino médio. Alternativamente, a redução do número de professores com base no número atual de alunos representaria uma economia de aproximadamente R $\$ 22$ bilhões (ou 0,33\% do PIB), dos quais R\$ 17 bilhões no ensino fundamental, e R\$ 5 bilhões no ensino médio (BANCO MUNDIAL, 2017, p. 129).

Conforme mencionamos anteriormente, a razão eficiente entre professor $\mathrm{X}$ aluno surge como uma das principais medidas sugeridas pelo Banco Mundial. Parece-nos interessante destacar tal fato, pois se, por um lado, certamente existem inúmeros professores cuja carga horária se encontra muito abaixo da estabelecida via concurso público - excetuando a hora-atividade. Por outro, é evidente que uma parcela bastante significativa dos professores enfrenta, cotidianamente, cenário bastante diverso. Considerando tanto o Ensino Básico, quanto o Ensino Superior, não raro é encontrarmos salas de aula com cerca de 20 alunos.

No Ensino Superior, por sua vez, é bastante comum encontrarmos cursos cujo número de vagas ofertadas via Sistema de Seleção Unificada - SISU chega alcançar uma centena. Como exemplo desta situação, podemos verificar as listas de vagas informadas pelas Universidades Federais divulgadas, majoritariamente, ao final de 2017. No caso da Universidade Federal do Rio Grande - FURG, conforme lista de vagas, disponibilizada no site da Universidade, é possível verificar que a abertura de vagas oscila entre números mínimos de 10 vagas para o curso de Educação do Campo e máximos 100 vagas para o curso de Ciências Contábeis

\begin{tabular}{l|c|c|c|c|c|c} 
(C) Rev. Educ. Perspec. & Viçosa, $M G$ & v.9 & n.1 & p.174-191 & jan./abr. 2018 & eISSN 2178-8359 \\
\hline
\end{tabular}


(FURG, 2017). Em caso bastante semelhante, a Universidade Federal de Pelotas - UFPEL apresenta uma variação de 7 vagas em ofertas relacionadas aos cursos de Música e 132 vagas disponibilizadas ao curso de Direito (UFPEL, 2017). Ao contrário do que sustentam os dados do Banco Mundial, nos parece que o cenário de lotação das salas de aula do Ensino Básico ao Ensino Superior constitui-se em realidade comum nos processos educativos brasileiros.

Outro ponto destacado pelo Banco Mundial no documento que debate o ajuste fiscal do estado brasileiro discorre sobre os gastos constitucionalmente vinculados à área da Educação. Sobre esta questão o Banco Mundial salienta que:

\begin{abstract}
A vinculação constitucional dos gastos em educação a 25 por cento das receitas dos municípios também contribui para a ineficiência dos gastos. Municípios mais ricos, com altas taxas de receita corrente líquida por aluno, tendem a ser bem menos eficientes que municípios mais pobres. Logo, é provável que para cumprir as regras constitucionais, muitos municípios ricos sejam obrigados a gastar em itens que não necessariamente ampliem o aprendizado. [...]. Além disso, esse gasto adicional muitas vezes não é necessário, e logo não resulta em maior aprendizado. A consequência é um aumento ainda maior da ineficiência (BANCO MUNDIAL, 2017, p. 130-131).
\end{abstract}

Vemos, segundo os argumentos apresentados neste documento, que as garantias obtidas pela luta dos movimentos sociais e entidades civis para que se vinculem percentuais mínimos de investimento na Educação se convertem, sob o prisma neoliberal, em saídas para o desequilíbrio fiscal do estado brasileiro. Fica nítido também, de acordo com a compreensão disposta no documento, que o gasto adicional com despesas públicas não necessariamente resulta em maior aprendizado, no que concordamos plenamente. Parece-nos, em direta contraposição com o afirmado no documento, que o corte de recursos - ou na linguagem usual do mercado financeiro, o desinvestimento - não contribui aos níveis de aprendizado socialmente necessários, pois, dado o sucateamento visível de inúmeras instalações escolares, algumas delas inclusive fazendo uso de material industrial como containers para suprir a demanda de salas de aula, sugerir a desvinculação do piso mínimo de investimento significa decretar a impossibilidade de manutenção de inúmeras instituições de ensino.

O terceiro eixo foco de ajuste mencionado pelo Banco Mundial em publicação supracitada versa sobre as despesas públicas para com a Educação Superior, comparando a média de gastos das Universidades Federais para com universidades estaduais e privadas. Segundo o documento:

Em média, um estudante em universidades públicas no Brasil custa de duas a três vezes mais que estudantes em universidades privadas. Entre 2013 e 2015, o custo médio anual por estudante em universidades privadas sem e com fins lucrativos foi de aproximadamente $\mathrm{R} \$ 12.600$ e $\mathrm{R} \$ 14.850$, respectivamente. Em universidades federais, a média foi de $\mathrm{R} \$ 40.900$. Universidades públicas estaduais custam menos do que as federais, mas ainda são muito mais caras do que as privadas, custando aproximadamente $\mathrm{R} \$ 32.200$. O custo por aluno dos institutos federais, a maior parte fundada desde 2008, é de aproximadamente R\$27.850 (BANCO MUNDIAL, 2017, p. 131). 
No documento são mencionadas ainda ponderações sobre o valor agregado dos ensinos público e privado, especificando apenas que os dados analisados pelo Banco Mundial se baseiam em larga medida nos dados fornecidos via Exame Nacional de Desempenho dos Estudantes - ENADE. No documento, mesmo com as ponderações sobre o valor agregado da formação em instituições públicas ou privadas à formação dos estudantes universitários, não há menção de qualquer problematização acerca da eficácia dos métodos avaliativos utilizados tanto pelo governo, quanto pelo próprio Banco Mundial.

A análise estritamente feita a partir do custo por aluno nas instituições públicas ou privadas desconsidera ainda todo o aparato disponível nas Instituições Públicas de Ensino Superior, que subsidiam práticas educativas, culturais, políticas e econômicas não somente aos estudantes matriculados em cursos de graduação e pós-graduação, possibilitando a toda comunidade em que se inserem as IES o acesso cultural não ofertado por Estados e Municípios. Consideramos que esta seja apenas uma das múltiplas possibilidades de análise do impacto positivo das IES públicas para os contextos em que estas se inserem. Para além da óbvia inserção de cursos de graduação e pós-graduação, são poucos os casos em que Instituições Privadas de Ensino Superior demonstram tamanha capilaridade nas comunidades em que se inserem. A multiplicação de cursos a distância e semipresenciais ofertados por instituições privadas de ensino também é fator que pesa no distanciamento entre o ambiente comunitário e tais instituições.

Vemos, de acordo com o estabelecido no relatório sobre o ajuste fiscal brasileiro que questões de amplo impacto são negligenciadas no debate, em detrimento da defesa irrestrita dos interesses do capital estrangeiro, das corporações internacionais, da iniciativa privada e do ideário neoliberal. O ajuste ainda é mencionado pelo Banco Mundial (2017) como questão urgente a fim de que se possa reencontrar o equilíbrio fiscal do estado brasileiro. Como movimento assertivo do governo Temer em relação às sugestões do relatório do Banco Mundial, parece ser possível percebermos, por meio da Emenda Constitucional $n^{\circ} 95$ de dezembro de 2016 (BRASIL, 2016a) que limita os gastos públicos, conhecida também como PEC do Teto de Gastos, que há uma mobilização clara de atendimento por parte do governo aos interesses do grande Capital.

Em outras medidas desenvolvidas pelo Governo Temer também é possível percebermos tal relação orgânica entre os interesses do governo e os da iniciativa privada. Um dos exemplos é o veto presidencial ao cumprimento orçamentário das metas inscritas no Plano Nacional de Educação, conforme mensagem de veto de número 277 de 2017 (BRASIL, 2017). Neste sentido também se coaduna o Decreto no 9.262 de 9 de janeiro de 2018 (BRASIL, 2018), em que ficam extintos diversos cargos públicos, dentre os quais inúmeros cargos necessários à Educação Pública, como pedagogos, geógrafos, pesquisadores e técnicos em assuntos educacionais, nas mais diversas lotações de serviço público.

\begin{tabular}{l|c|c|c|c|c|c|} 
(C) Rev. Educ. Perspec. & Viçosa, $M G$ & v.9 & n.1 & p.174-191 & jan./abr. 2018 & eISSN 2178-8359 \\
\hline
\end{tabular}


Tais ações nos parecem evidenciar o sentido de realização do ideário neoliberal empreendido pelo Governo Temer. Conforme ressaltamos no decorrer do desenvolvimento deste artigo, tal ideário não se constitui em exceção perpetrada exclusivamente pelo governo Temer, mas perpassa as políticas de governos que expressam caráter menos explícito de apoio às dinâmicas neoliberais. Vimos também que, de forma geral, a totalidade da Educação Pública vem sofrendo com cortes de recursos e os ajustes fiscais recentemente aplicados.

\section{CONSIDERAÇÕES FINAIS}

Procuramos ao longo deste artigo sustentar a ideia de que há um vínculo orgânico entre o que acontece no conjunto da Educação e os interesses que perpassam o mercado, dados pelo grande Capital, pela iniciativa privada, pelas grandes corporações, pelos conglomerados educativos e midiáticos, dentre outras diversas influências que estão dispostas na Educação. Nossa intenção com esta linha argumentativa era a de evidenciar que questões conjunturais se constituem em elementos prioritários na prática docente. A docência, dessa forma, como parte do conjunto da Educação não passa despercebida destes interesses e com isso a prática das educadoras e educadores constitui-se, em parte, pelos reflexos que estes elementos conjunturais impõem ao que se faz em sala de aula.

Queremos dizer com isso que aquilo que fazemos em sala de aula, o que fazem os docentes de diversas áreas é profundamente condicionado por interesses que aparentemente não constam explícitos no cotidiano docente. Seria certamente óbvio supor que os interesses que influenciam as práticas educativas são aqueles dados pelo envolvimento de estudantes, de professores, do corpo diretivo e da comunidade escolar. No entanto, como explicar a influência destes outros elementos que se ocultam em nossas vivências em sala de aula? Como se pode planejar e executar um bom plano de aula, com referências de grande envergadura na área da Educação, debates reflexivos, críticos e independentes se não temos garantias de que sequer os estudantes tenham disposição física para estar em sala de aula, dada a sobrecarga que muitos enfrentam? E como mensurar o "sucesso" das aulas desenvolvidas por professores que enfrentam, além da carga cotidiana que cada um de nós assume, a desvalorização salarial, a falta de estabilidade profissional e a desvalorização dada à área das ciências humanas nos currículos brasileiros?

Sabemos que tais questionamentos escapam à capacidade de resposta que podemos oferecer, dada magnitude destes elementos nos debates da Educação. Porém, pensamos que seja fundamental retomar tais interrogações a fim de que sempre sejam ponderados tais condicionantes na avaliação daquilo que considerarmos como atividades de sucesso ou insucesso nas práticas educativas. Isto significa ainda nos direcionarmos em sentido contrário 
à maré de críticas individualistas à postura dos professores, à responsabilização individual das e dos docentes pelo que é satisfatório ou insatisfatório dentro da sala de aula.

Com tal argumentação não queremos dizer que desqualificamos as responsabilidades inerentes à postura dos docentes, afinal, sabemos de nossa profunda importância no processo de produção de conhecimentos e posturas críticas e reflexivas em sala de aula. Mas, cabe ressaltarmos também que a culpabilização dos docentes pelos problemas educativos brasileiros não pode ser considerada justa, dados os condicionantes que sustentamos ao longo de nossa linha de raciocínio expostas nos três tópicos desenvolvidos neste artigo.

Por fim, consideramos que as relações entre as políticas públicas de Educação brasileiras e os interesses do mercado, ou do grande Capital, afetam de forma categórica as práticas das educadoras e educadores. Tal relação dita, em última instância, um conjunto de possibilidades às práticas docentes, fazendo com que, em muitos casos, podem os docentes produzir os melhores planejamentos e atividades e mesmo assim não alcançarem um desenvolvimento satisfatório nas práticas em sala de aula.

Conforme procuramos explicitar durante o desenvolvimento de nosso artigo, os condicionantes materiais impostos pelo vínculo estabelecido entre o Estado e o Mercado acabam por impactar diretamente nas práticas educativas como um todo e, certamente, na especificidade do trabalho docente. Entendemos que esta relação se torna mais evidente porque a prática docente responde, para além das dinâmicas mais imediatas dadas pela relação entre docentes e estudantes, a uma série de instâncias pedagógicas.

O planejamento que fazemos - enquanto docentes - se relaciona aos conteúdos que precisam ser trabalhados, aos objetivos finais de nossa prática de sala de aula, às temáticas que precisam ser transversalizadas e a uma série de outros compromissos pedagógicos que assumimos no processo de docência. A organização destes conteúdos, temas e compromissos se desenvolve também em direto vínculo com os diversos documentos, estudos e legislações que orientam aquilo que se deve fazer na escola. Estes, por sua vez, são produzidos a partir dos múltiplos interesses dados na sociedade. No caso que tratamos, por exemplo, pela força dos interesses de setores da sociedade aliados ao grande Capital.

No início deste artigo começamos estabelecendo que múltiplas poderiam ser as abordagens aqui desenvolvidas. No entanto, nosso esforço se encaminhou à explicitação dos interesses neoliberais na totalidade da Educação por vermos o caminho que liga os interesses dispostos nas Políticas Públicas ao cotidiano dos docentes. Assim, nosso foco foi, a todo o momento, relembrar que estes interesses, ainda que possam ser considerados distantes da prática de sala de aula, perpassam nosso fazer cotidiano, seja sob a forma da prioridade à determinados conteúdos, seja nas opções metodológicas utilizadas ou na própria relação que

\begin{tabular}{l|c|c|c|c|c|c|} 
(C) Rev. Educ. Perspec. & Viçosa, $M G$ & v.9 & n.1 & p.174-191 & jan./abr. 2018 & eISSN 2178-8359 \\
\hline
\end{tabular}


desenvolvemos com os estudantes, em virtude do tempo da Economia e da Política, também cada vez mais aligeiradas.

Por entendermos a organicidade e força deste vínculo entre o que é feito em sala de aula, no conjunto da Educação e de interesses macroeconômicos, que sustentamos a necessidade de retomarmos um estudo o mais complexo quanto for possível e que considere tal relação, como pressuposto às práticas educativas.

\section{REFERÊNCIAS}

BANCO MUNDIAL. La enseñanza superior: las lecciones derivadas de la experiencia (el desarrollo en la práctica). Washington, D.C.: BIRD/Banco Mundial, 1995.

BANCO MUNDIAL. Prioridades y estratégias para la educación. Washington DC. EUA, 1996.

BANCO MUNDIAL. Aprendizagem para todos: investir nos conhecimentos e competências das pessoas para promover o desenvolvimento. Washington, D.C.: BIRD/Banco Mundial, 2011.

BANCO MUNDIAL. Um ajuste justo: análise da eficiência e equidade do gasto público no Brasil. Washington, D.C.: BIRD/Banco Mundial, 2017.

BOITO JUNIOR, Armando. Política neoliberal e sindicalismo no Brasil. Tese de Livre Docência. Departamento de Ciência Política. Universidade Estadual de Campinas, 1998.

BRASIL. Lei no 9.394, de 20 de dezembro de 1996. Estabelece as diretrizes e bases da educação nacional. Brasília, 1996.

BRASIL. Lei $\mathbf{n}^{\mathbf{0}} \mathbf{1 0 . 6 3 9 / 0 3}$. Altera a Lei $\mathrm{n}^{\mathrm{o}}$ 9.394, de 20 de dezembro de 1996, que estabelece as diretrizes e bases da educação nacional, para incluir no currículo oficial da Rede de Ensino a obrigatoriedade da temática "História e Cultura Afro-Brasileira", e dá outras providências. Brasília, 2003.

BRASIL. Lei no 11.096/05. Institui o Programa Universidade para Todos - PROUNI, regula a atuação de entidades beneficentes de assistência social no ensino superior; altera a Lei $\mathrm{n}^{\circ}$ 10.891, de 9 de julho de 2004, e dá outras providências. Diário Oficial [da República Federativa do Brasil]. Brasília, 2005.

BRASIL. Emenda Constitucional no 53/06. Dá nova redação aos art. 7º , 23, 30, 206, 208, 211 e 212 da Constituição Federal e ao art. 60 do Ato das Disposições Constitucionais Transitórias. Brasília, 2006. 
BRASIL. Decreto no 6.096/07. Institui o Programa de Apoio a Planos de Reestruturação e Expansão das Universidades Federais - REUNI. Brasília, 2007.

BRASIL. Lei $\mathbf{n}^{\circ}$ 11.645/08. Altera a Lei no 9.394, de 20 de dezembro de 1996, modificada pela Lei $\mathrm{n}^{\circ} 10.639$, de 9 de janeiro de 2003 , que estabelece as diretrizes e bases da educação nacional, para incluir no currículo oficial da rede de ensino a obrigatoriedade da temática "História e Cultura Afro-Brasileira e Indígena". Brasília, 2008.

BRASIL. Lei no 11.684/08. Altera o art. 36 da Lei no 9.394, de 20 de dezembro de 1996, que estabelece as diretrizes e bases da educação nacional, para incluir a Filosofia e a Sociologia como disciplinas obrigatórias nos currículos do ensino médio. Brasília, 2008a.

BRASIL. Lei $\mathbf{n}^{\mathbf{0}} \mathbf{1 2 . 2 0 2 / 1 0}$. Altera a Lei $\mathrm{n}^{\mathrm{o}}$ 10.260, de 12 de julho de 2001, que dispõe sobre o Fundo de Financiamento ao Estudante do Ensino Superior - FIES (permite abatimento de saldo devedor do FIES aos profissionais do magistério público e médicos dos programas de saúde da família; utilização de débitos com o INSS como crédito do FIES pelas instituições de ensino; e dá outras providências). Brasília, 2010.

BRASIL. Análise sobre a Expansão das Universidades Federais 2003 a 2012. Brasília, 2012 .

BRASIL. Decreto de 27 de junho de 2016. Torna sem efeito os Decretos de 10 de maio de 2016, publicados no Diário Oficial da União do dia 11 de maio de 2016, Seção 2, página 1, referentes aos membros abaixo indicados para comporem as Câmaras do Conselho Nacional de Educação, com mandato de quatro anos. Brasília, 2016.

BRASIL. Emenda Constitucional $\mathbf{n}^{\mathbf{0}}$ 95/16. Altera o Ato das Disposições Constitucionais Transitórias, para instituir o Novo Regime Fiscal, e dá outras providências. Brasília, 2016a.

BRASIL. Decreto 9.262/18. Extingue cargos efetivos vagos e que vierem a vagar dos quadros de pessoal da administração pública federal, e veda abertura de concurso público e provimento de vagas adicionais para os cargos que especifica. Brasília, 2018.

BRASIL. Veto ao Projeto de Lei n 1, de 2017. Mensagem n. 277, Brasília, 2017.

CHAVES, Vera Lúcia Jacob. Expansão da privatização/mercantilização do ensino superior brasileiro: a formação dos oligopólios. Educação \& Sociedade, Campinas, v. 31, n. 111, p. 481-500, abr./jun. 2010.

CHAUI, Marilena. A universidade operacional. Avaliação, Campinas, v. 4, n. 3, p. 3-8, 1999.

DAVIES, Nicholas. O Governo Lula e a educação: a deserção do estado continua? Educação \& Sociedade, Campinas, v. 25, n. 86, p. 245-252, abr. 2004.

FURG. Vagas autorizadas. Rio Grande, 2017. Disponível em: <http://www.sisu.furg.br/index.php/cursos/vagas-autorizadas>. Acesso em: 15 jan. 2018.

\begin{tabular}{l|c|c|c|c|c|c|} 
(C) Rev. Educ. Perspec. & Viçosa, $M G$ & v.9 & n.1 & p.174-191 & jan./abr. 2018 & eISSN 2178-8359 \\
\hline
\end{tabular}


LEHER, Roberto. Um novo senhor da educação? A política educacional do Banco Mundial para a periferia do capitalismo. São Paulo, n. 1, out. 1999.

LIMA, Kátia Regina de Souza. O Banco Mundial e a educação superior brasileira na primeira década do novo século. Revista Katálysis, Florianópolis, v. 14, n. 1, p. 86-94, jan./jun. 2011.

MENDES, Marcos. A Despesa Federal em Educação: 2004-2014. Boletim Legislativo no 26, de 2015. Brasília: Núcleo de Estudos e Pesquisas/CONLEG/Senado, abr. 2015. Disponível em: 〈www.senado.leg.br/estudos〉. Acesso em: 15 jan. 2018.

SAAD FILHO, Alfredo. Neoliberalismo: Uma análise marxista. Marx e o Marxismo, v. 3, n. 4, jan./jun. 2015.

UFPEL. Termo de Adesão 1 ${ }^{\text {a }}$ edição de 2018. Pelotas, 2017. Disponível em: <https://wp.ufpel.edu.br/sisu/files/2017/10/termo_adesao_634_UFPEL-Retificado-17novembro.pdf>. Acesso em: 15 jan. 2018. 


\title{
NOTAS
}

\begin{abstract}
i Ao longo do artigo nos referiremos diversas vezes às categorias "Neoliberal/Neoliberalismo". Para caracterizar as mesmas nos subsidiamos na literatura marxista em que vemos que "A ideologia neoliberal contemporânea é, essencialmente, um liberalismo econômico que exalta o mercado, a concorrência e a liberdade de iniciativa empresarial, rejeitando de modo agressivo, porém genérico e vago, a intervenção do Estado na economia. Esse liberalismo econômico é distinto do liberalismo político, interessado nos direitos individuais do cidadão e num regime político representativo e adequado ao exercício daqueles direitos. A ideologia neoliberal retoma o antigo curso econômico burguês, gestado na aurora do capitalismo, e opera com esse discurso em condições novas (BOITO JUNIOR, 1998, p. 16)", ou ainda, podendo ser sustentado "[...] de quatro maneiras distintas, porém intimamente relacionadas: como um conjunto de ideias inspiradas nas escolas econômicas austríaca e de Chicago e no ordoliberalismo alemão, e elaboradas sob a égide da Sociedade do Mont Pèlerin; como um conjunto de políticas, práticas e instituições inspiradas e/ou validadas por essas ideias; como uma ofensiva de classe liderada pelo Estado contra os trabalhadores e os pobres, em nome da burguesia em geral ou das finanças em particular; e como uma estrutura material de reprodução econômica, social e política, implicando que o neoliberalismo é o modo de existência do capitalismo contemporâneo ou um sistema de acumulação" (SAAD FILHO, 2015, p. 59).

ii O FUNDEB diferencia-se do FUNDEF especialmente pela abrangência da alocação dos recursos que constituem o fundo. Enquanto que os recursos determinados à Educação provenientes do FUNDEF se destinavam à subvenção do Ensino Fundamental, a destinação de recursos a partir da criação do FUNDEB passa a incorporar também os níveis da Educação Infantil, do Ensino Fundamental e do Ensino Médio.
\end{abstract}

\section{Agradecimentos}

À Capes e ao CNPq pelo apoio financeiro na realização deste artigo.

\section{SOBRE OS AUTORES}

${ }^{1}$ Alana das Neves Pedruzzi - Mestre e Doutoranda em Educação Ambiental pelo Programa de PósGraduação em Educação Ambiental, da Universidade Federal do Rio Grande. E-mail: alanadnp@gmail.com - ORCID: http://orcid.org/0000-0002-3991-9933

2 Tamires Lopes Podewils - Mestre e Doutoranda em Educação Ambiental pelo Programa de PósGraduação em Educação Ambiental, da Universidade Federal do Rio Grande. E-mail: podewils.t@gmail.com - ORCID: http://orcid.org/0000-0002-9683-0214

3 Fernando Nunes Oliveira - Doutor em Filosofia pela PUCRS, tendo realizado Doutorado Sanduíche na Universidade de Princeton com bolsa FULBRIGHT/CAPES. E-mail: fernandon.oliveira@yahoo.com.br - ORCID: http://orcid.org/0000-0002-1086-2056 